\title{
Commentary on Microtonal Analysis of "Blue Notes" and the Blues Scale by Court B. Cutting
}

\author{
TILO HÄHNEL[1] \\ University of Paderborn
}

\begin{abstract}
This commentary discusses the target paper Microtonal Analysis of "Blue Notes" and the Blues Scale by Court B. Cutting. Overall, the paper is an interesting and very valuable attempt to shed light on the intonation practice of blue notes in traditional blues music, using an empirical approach which is based in modern acoustic measurements. While the approach and empirical results presented in the target paper undoubtedly have their merits, the paper nonetheless raises some methodological and conceptual questions, leading to some further thoughts that are discussed in this commentary. The issues raised in this commentary might serve as guidance for future empirical investigations into the nature and usage of blue notes.
\end{abstract}

Submitted 2018 October 7; accepted 2018 October 18.

CUTTING presents a study in which he measured the average pitch of tones in 15 'classic' blues performances to determine the pitch of so-called blue notes. The topic is interesting and, as the author states, empirical investigations have long been overdue. So far, the most important studies of blue notes are still the ones conducted by Titon (1977), Evans (1982), and Kubik (2008). Therefore, I welcome any empirical approach based on actual frequency measurements that is suitable to substantiate or challenge the current theory behind the usage of blue notes. Nevertheless, there are four points worth discussing in brief.

Firstly, all results are presented in detail and with sufficient transparency; however, the paper would have benefitted from a clear, final result presented at the end of the Results and in the Conclusions section. The current impression that the paper does not converge on a few main results may be because the author did not formulate a clear research question or theory, from which a clear hypothesis could be derived or constructed. The study is rather a Proof-of-Concept for a methodology that measures pitch distributions. The results being discussed are nevertheless interesting, because the quantitative approach of the study has many advantages, and certainly constitutes an important supplement to close-listening approaches. In this way, the methodology presented in the target paper can be regarded a computational tool for supporting studies of individual recordings or singers. Still, it seems a shame that the author did not start from a quantitative hypothesis. With such a hypothesis - possibly derived from the related literature on blues analysis discussed at the beginning of the target paper - the author would have been able to substantiate a theory, or even decide between two rivalling theories. Instead, the results contribute some additional observations and partially replicate findings from previous work in that area. In summary, the study shows that there are some relatively stable pitches and some wider clusters of tones which are suggestive of the tonal regions that Titon (1977) and Evans (1982) had identified decades ago by close listening. However, even as a replication study the paper would have needed a clear hypothesis. For a quantitative study, the number of recordings analyzed was quite small. As Cutting argues, the difference between his and Titons results may be explained by the fact that Titon analysed many more blues recordings, despite his time consuming and effortful close-listening approach. However, running a statistical and computer-aided analysis could have easily dealt with more instead of fewer recordings, and therefore it appears like a lost opportunity in this respect.

Secondly, there are possible issues with Cutting's assumption of a stable pitch. In my own empirical research based on pitch measurements (Hähnel 2015), I hypothesized that the slurring of the blue note might be the key for its understanding; particularly the linear upwards slide from the minor to the major third, or the slur going from the second to any third, can be found in many blues performances (in vocal performances as well as in bottle-neck guitar playing). The traditional view from Western music theory and analysis generally assumes that a pitch is something stable. For scholars from this tradition, it may be hard to imagine that a moving pitch rather than a static tone could be the basis for musical 
structures. In fairness, Cutting mentions the slurring of blue notes briefly, but this is certainly an aspect to elaborate upon in the future. Of course, the investigation of slurs falls outside the scope of the analysis as it is presented here because the study is based on averaging of pitch frequencies and hence precludes slurs from being observed and measured as distinct musical objects.

Thirdly, and following on from the previous point, a mere analysis of pitch neither considers the singing voice and singing style, nor does it consider the melodic context. For instance, the tonic cluster does not indicate whether the deviations from the mean are due to 'bad intonation', a jittery voice, a distinct vibrato or the intentional use of slurs, all of which might affect the cluster average and shape. Therefore, the distribution of pitches does not indicate any precise intonation patterns. In addition, it is possible that the tonic pitch varies throughout the recording; particularly in a-Capella singing, the tonic may gradually shift over time. This would result in a cluster where the tones at one cluster boundary are predominantly sampled from the beginning of the recording and the opposite cluster boundary represents the tones from the end of the recording. There might even be technical reasons that contribute to a wider cluster: since some of these recordings are in bad condition (if recalled correctly), it is also important to know that there might be pitch differences due to an unstable rotation of the record in the transformation process or even in the recording process. The melodic context might also play a role, and it would be important to assess the degree to which systematic pitch deviations can be identified with respect to melodic structures. For example, are pitches generally lower than expected when they follow a melodic high point? Are pitches consistently lower or higher before or after a tonic? Some questions might be answered by comparing the range of different clusters (i.e. gradual pitch-shifts throughout the whole recording), but others not. The method and results presented in the paper do at least raise these questions. Obviously, these cannot all be answered in a single study and clearly require careful treatment in future investigations, but as a minimum these questions should be discussed briefly.

Fourth, Cutting's comparison of cluster means against theoretical frequency ratios from the just intonation tuning is generally compelling. Unfortunately, the missing hypothesis mentioned at the beginning remains an issue: How close do empirical measurements and theoretical intervals need to be, to decide for or against a theoretical ratio? For instance, a major third may be around 400 cents; when it turns out a bit flat, then it may match 'just intonation' tuning. When it is larger, then it can correspond to 'Pythagorean' tuning. But how close must the results get? There was no test of statistical significance, effect size or test power for the deviation of cluster-means from a theoretical ratio. The problem is that these interpretations imply a specific intention or at least a subconscious or otherwise systematic behavior on behalf of the musician. But it is difficult to derive such an interpretation from empirical measurements alone and without a clear hypothesis or prediction made a priori. Generally, the paper would have been substantiated by providing further statistical validation, such as tests for normality or differences.

Since the points stated above are all critical questions, it is worth stating again that, in general, Cutting's method appears robust and represents an interesting approach for further research. Therefore, these comments should be understood as an addition to the discussion on empirical approaches for understanding blues singing, and not as a critique of Cutting's approach.

\section{ACKNOWLEDGMENTS}

This article was copyedited by Scott Bannister and layout edited by Kelly Jakubowski.

\section{NOTES}

[1] Correspondence can be addressed to: Dr. Tilo Hähnel, Universität Paderborn, Musikwissenschaftliches Seminar Detmold/Paderborn, Hornsche Straße 39,32756 Detmold, Germany, tilo.haehnel@upb.de

\section{REFERENCES}

Evans, D. (1982). Big road blues: Tradition and creativity in the folk blues. Berkeley, CA: University of California Press. 
Hähnel, T. (2015). "Blues Falling Down Like Hail.” Vokaler Ausdruck in drei Spielarten des Blues. In: M. Pfleiderer, T. Hähnel, K. Horn and C. Bielefeldt (Eds.), Stimme, Kultur, Identität. Vokaler Ausdruck in der populären Musik der USA, 1900-1960 (pp. 233-268), Bielefeld: transcript.

Kubik, G. (2008). Bourdon, blue notes, and pentatonicism in the blues: An Africanist perspective. In D. Evans (Ed.), Ramblin' on my mind: New perspectives on the blues (pp. 11-48). Urbana, IL: University of Illinois Press.

Titon, J. T. (1977). Early downhome blues: A musical and cultural analysis. Chicago, IL: University of Illinois Press. 